\title{
Symptomatic parauretheral cyst in female neonate case report and review of literature
}

\author{
Bassam K. Al-Abbasi \\ Pediatric Surgery centre, Alkhansaia Hospital. Mosul
}

(Ann. Coll. Med. Mosul 2008; 34(2): 180-182).

Received: $2^{\text {nd }}$ Mar 2008; Accepted:15 ${ }^{\text {th }}$ Oct 2008.

\begin{abstract}
A female neonate with parauretheral cyst is rarely encountered in our surgical practice and uncommonly reported in literature. Nearly all these cases were asymptomatic.

In this paper I reported a case of symptomatic parauretheral cyst which required surgical management with excellent results functionally and cosmetically.
\end{abstract}

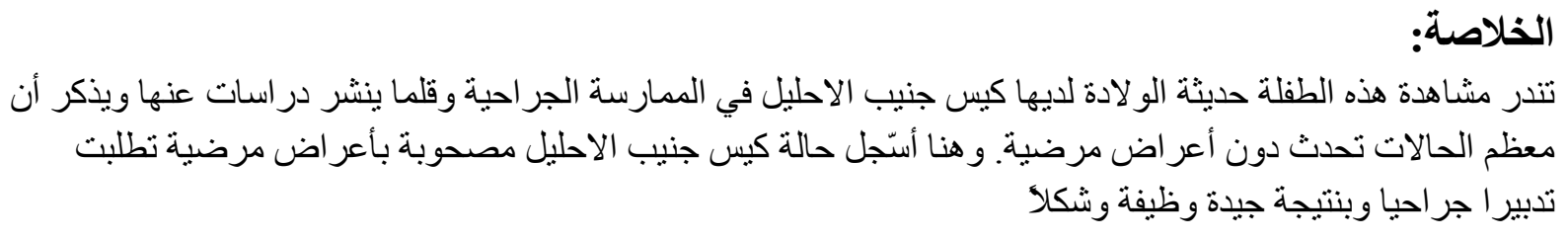

$\mathrm{P}$

arauretheral cyst (P.U.C) is a rarely reported lesion of female child especially in neonate ${ }^{(1-4)}$; it arises from obstruction and cystic dilatation of parauretheral or Skene's glands' ducts ${ }^{(1,2,4)}$.

The true incidence is variable, Ceylon et al reported 1-10 per 10,000 live birth $^{(2)}$ while Merlob et al reported 6 cases in 3026 new born females ${ }^{(5)}$. On the other hand Lee et al found 1 per 2074 incidence of female birth in their own series ${ }^{(6)}$. English literature reported only 37 cases in new born ${ }^{(2)}$.

Diagnosis of (P.U.C) depends on its location in relation to the urethra and demonstration of transitional epithelium in the cyst wall ${ }^{(7)}$.

Role of surgery in managing this problem is controversial, because it might disappear spontaneously within few months ${ }^{(1,4)}$, otherwise it might rupture spontaneously or could be managed by simple marsupialization or aspiration ${ }^{(3,4,8)}$.

Case report :
A 3days old female, a product of normal vaginal delivery was referred to our pediatric surgery center at Alkhansa'a hospital in Mosul, suffering from attack of difficult micturation and dribbling of urine with protruding mass from her genitalia, giving the impression of imperforate hymen.

The baby was admitted to our ward for assessment . On physical examination:the baby was mildly jaundiced weighing $2.8 \mathrm{~kg}$. Local examination showed intralabial cystic mass measuring $2 * 2 \mathrm{~cm}$ protruded between the labia minora, shiny, bluish to whitish in color ,obscuring urethral and vaginal openings arising from right side of urethral meatus as shown in fig( 1 ).

Abdominal examination revealed moderately distended urinary bladder with passage of urine from lateral aspect of the cyst on gentle pressure on the bladder. Ultrasound examination was normal. Other examinations were normal too. 
The parents were very anxious and worried about the baby, they were from rural area and thought that she has no vagina .We reassured the parents and reassessed the patient under general anesthesia, which confirmed our diagnosis of parauretheral cyst which was pushing the uretheral and vaginal openings and compressing them to left side. We introduced a Foly's catheter, followed by deroofing most of the cyst wall leaving the inner aspect intact. A creamy material came out and the marsupialized edges were interrupted by fine absorbable suture material; fig(2).

Post operatively the infant did very well, Foly's catheter removed next day The infant passed urine normally and discharged very well with no complications for the last 2 years period of follow up; fig.(3).

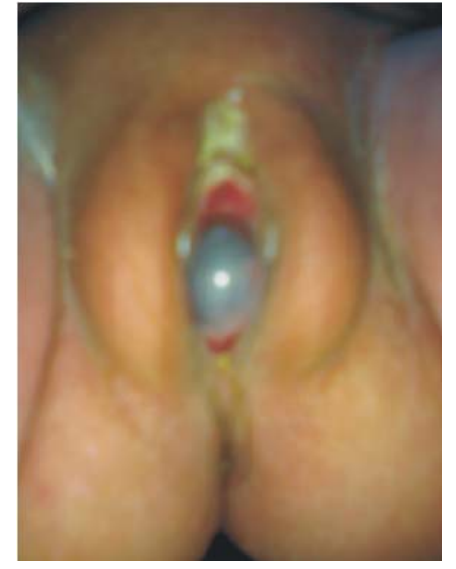

Fig. 1:preoperative interlabial cyst.

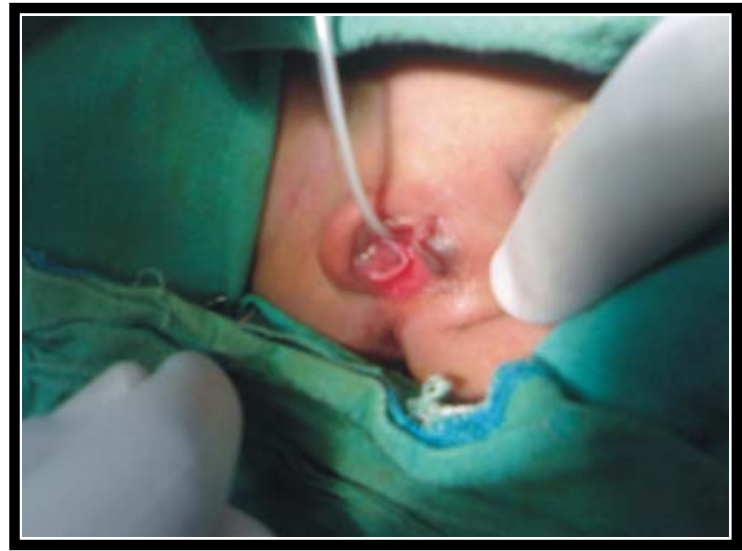

Fig.(2) intraoperative deroofing .

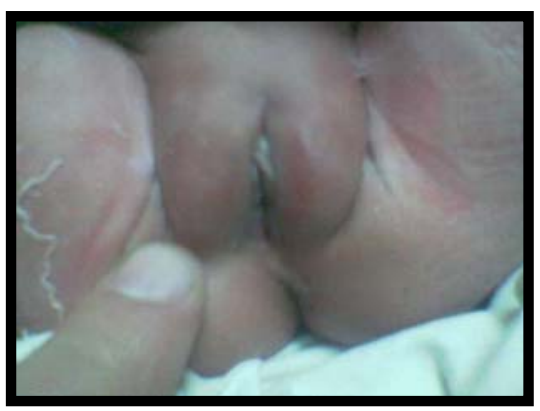

Fig.3:3weeks postoperative showing normal appearance of genitalia.

\section{Discussion:}

Paraurertheral ducts are about 6-30 in number as described by Huffman ${ }^{(9)}$. The largest 2 ducts commonly referred to as Skene's duct opened into the external uretheral meatus ${ }^{(2,7,10)}$. Although the exact cause of cyst development is not well established, yet the most acceptable theories are inflammation and obstruction of the duct or dislocation of urothelium from sinus urogenitalis to an adjacent area ${ }^{(1)}$.

Paraurethral ducts are infrequently reported in the literature. Bergner et al reported 3 cases in $1985^{(8)}$; Herek et al reported one case in $2000^{(1)}$. In 1998 Tsuda et al reported one case in Japan ${ }^{(11)}$ while in 2003 Fathi et al reported 6 cases over 17 years period ${ }^{(4)}$ but the largest series was reported by Sharifi et al who reported 25 cases published in $2004^{(12)}$.

The above reports suggest the rarity of this type of lesion all over the world and limited reported cases with different modes of treatment. 
In our country this is the first case reported till now over the last 12 years this is could be due to either under have reporting of such problem or it may go unrecognized because it either disappeared spontaneously with time or might have ruptured before identification.

The fate of the cyst is subject to controversy, some might undergo spontaneous regression ${ }^{(1,4)}$, others might end with spontaneous rupture ${ }^{(2,3,7,8)}$.

The diagnosis of such problem is made easy by simple clinical assessment to ensure normal urethral meatus and patent vagina ${ }^{(1,7)}$ aided by simple urological investigation like ultrasound to exclude prolapsing ectopic ureterocele and some times cystourethroscopy might be in need to differentiate it from ureterocele, urethral diverticulum or tumor ${ }^{(3,8,12)}$.

Clinical assessment with good light and relaxation under general anesthesia after ultrasound of abdomen will be sufficient for the diagnosis. Identification of urethral meatus and vagina with its hymen exclude imperforate hymen. With simple pressure on the cyst, we can differentiate it from prolapsed ureterocle as with collapsing of the cyst passage of urine from urethral meatus is observed in cases of prolapsed ureterocele.

Nearly all reported cases were asymptomatic, thus conservative management was the rule waiting for spontaneous regression. But in many cases surgical management is preferred either by simple needle aspiration ${ }^{(6,11)}$, marsipulization or even excision of the cyst ${ }^{(2,3,4,7,8,12)}$.

In our patient there was a urinary retention, large cyst, more than $2 \mathrm{~cm}$ and an anxious family. So waiting for spontaneous regression will be unreliable and simple drainage and deroofing leaving the inner part of the cyst intact ended by simple marsupialization was the perfect and most appropriate for the patient and was more satisfactory for the parents.

From this review we may conclude the following:-

1. Symptomatic cyst should be treated surgically by deroofing and marsupialization.

2. Waiting for spontaneous regression for a symptomatic cyst will be fruitless as it takes long period of time ((few months)) and add psychological burden on the parents.
3. Parauretheral cyst is not a very rare problem as there may be unrecognized or unreported cases.

\section{References:}

1. Ö. HereK, H. Ergin, D. Karaduman, O. cetin, M. A. Aksit. Parauretheral cyst in newborn: A case report and review of literature, Eur. J. pediatr surg. 2000; 10: $65-67$.

2. Ceylan H., Ozokutan BH,Karakok M, Buyukbeses.parauretheral cyst:is conservative management always appropriate? Eur.J Pediatr. Surg. 2002 Jun;12(3):212-4.

3. Blavias JG, pais VM, Retik AB. parauretheral cyst in female neonate. Urology, 1076; 7 : $504-507$.

4. Fathi K, Pinter A. parauretheral cyst in neonates. case reports. Acta pediatr. 2003 Jun; 92(6): 758-9.

5. Merlob P, Bahari C, liban E, Reisner SH. cyst of female external genitalia in the newborn infant. Am J Obstet. Gynecol 1978; 13: 2; 607610.

6. Lee $\mathrm{NH}$, Kim Sy; Skene's duct in female newborn. J pediatr surg 1992; 27: 15-17.

7. Kimbrough HM, Vaughan ED, skene $s$ duct in a newborn: case report and review of literature. J Urol 1977; 117:387 - 388.

8. Bergner DM. Parauretheral cyst in newborn. South Med J 1985; 78 Jun:749 - 750.

9. Huffman JW; The detailed anatomy of the parauretheral duct in the adult human female, AMJ Obstet Gynecol. 1948; 55: 86.

10.Skene AJC. The anatomy and pathology of tow important glands of the female urethera . Am J obstet 1880; 13: 265.

11.Tsuda $\mathrm{S}$, kanda $\mathrm{S}$, koga $\mathrm{S}$, saito $\mathrm{Y}$. parauretheral cyst in a female neonate: a case report. hinyokika. 1998 Dec; 44 (12): 891 -2.

12.Sharifi -Aghdas F, Ghaderian N. female parauretheral cyst: experience of 25 Cases. BJU Int. 2004 Feb;93(3):353-6. 